\title{
Comparison of Mechanical Deflection and Maximum Stress of 3C SiC- and Si-Based Pressure Sensor Diaphragms for Extreme Environment
}

\author{
${ }^{a}$ Noraini Marsi, ${ }^{a}$ Burhanuddin Yeop Majlis, SMIEEE, ${ }^{a}$ Azrul Azlan Hamzah and ${ }^{b}$ Faisal Mohd-Yasin, SMIEEE \\ anstitute of Microengineering and Nanoelectronics (IMEN) \\ Universiti Kebangsaan Malaysia (UKM) \\ 43600 UKM Bangi, Selangor, Malaysia \\ bueensland Micro- and Nanotechnology Centre (QMNC) \\ Griffith University, 4111, Brisbane, QLD, Australia \\ Email: burhan@vlsi.eng.ukm.my
}

\begin{abstract}
The design of a capacitive-sensing pressure sensor for extreme environment is proposed in this project. The movable diaphragm (top plate) is made of either cubic silicon carbide (3C$\mathrm{SiC}$ ) or Silicon (Si), while the fix diaphragm (bottom plate) is made of Si. This paper specifically compares the mechanical performance of the movable diaphragm utilizing both materials. Two important parameters associated with the behavior of the diaphragm are examined, namely the maximum deflection and maximum stress, and they are simulated at a pressure of 0-100 $\mathrm{MPa}$, and at temperature of $27-1000{ }^{\circ} \mathrm{C}$. The graphs of maximum deflection and stress $v s$ pressures at different temperatures and thicknesses are plotted to summarize the data. SiC diaphragm has lower deflection and stress compares to $\mathrm{Si}$ diaphragm at different thicknesses, pressures and temperatures. Then, a linear regression analysis is performed to determine the $R$-square value. It is shown from these analyses that $\mathrm{SiC}$ diaphragm exhibits better linear behavior compares to Si diaphragm. Generally, this work proves that $\mathrm{SiC}$ is a better material over $\mathrm{Si}$ for the development of a pressure sensor at extreme environment.
\end{abstract}

Keywords: silicon carbide (SiC), pressure sensor, harsh environment, diaphragm

\section{INTRODUCTION}

The operating temperature inside the gas turbine engine is typically greater than $300^{\circ} \mathrm{C}$ [1]. However, the silicon-based MEMS pressure sensor could only operate below this point due to the limitation of its material properties. In such extreme environment, $\mathrm{SiC}$ is the best material to replace $\mathrm{Si}$ because it can operates up to $1000^{\circ} \mathrm{C}$ [2]. In addition, $\mathrm{SiC}$ has more advantages at this environment due to its chemical inertness and corrosion resistance, and an extremely low coefficient of thermal expansion and high Young's Modulus. The latter is a good mechanical advantage because that makes $\mathrm{SiC}$ more immune to stress effects from deflection and thermal shock. Electrically speaking, $\mathrm{SiC}$ has an excellent properties compares to $\mathrm{Si}$ as well, namely a larger bandgap $(2.3-3.4 \mathrm{eV})$, a higher breakdown field $\left(30 \times 10^{5} \mathrm{~V} / \mathrm{cm}\right)$, a higher thermal conductivity $(3.2-4.9 \mathrm{~W} / \mathrm{cm} \mathrm{K})$, and a higher saturation velocity $\left(2 \times 10^{7} \mathrm{~cm} / \mathrm{s}\right)$ [3]. This paper will demonstrate the superiority of $\mathrm{SiC}$ material over $\mathrm{Si}$ as the pressure sensor diaphragm through a series of simulations.

\section{THEORY AND DESIGN}

\section{A. Design of a capacitive pressure sensor}

A structural model for the pressure sensor is shown in Figure 1. It consists of two components to make the parallelplate structure; the first is the top diaphragm as the movable plate, and the second is a bottom substrate as a fixed plate. The pressure signal comes from the top and generates the stress-deformation of the movable diaphragm, which modulates the sealed air gap length. The corresponding differential capacitance value between the top and bottom plates is measured as the electrical output. In this design, the square shape diaphragm with the area of $400 \mu \mathrm{m}^{2}$ is employed. The thickness of the top movable diaphragm is simulated at the following points: $0.05 \mu \mathrm{m}, 0.1 \mu \mathrm{m}, 0.2 \mu \mathrm{m}, 0.3$ $\mu \mathrm{m}, 0.5 \mu \mathrm{m}$ and $1.0 \mu \mathrm{m}$ to study the stress deformation of both $\mathrm{SiC}$ and $\mathrm{Si}$ membranes at different thicknesses.

TABLE I Material Properties of Tested Materials [4]

\begin{tabular}{|l|c|c|}
\hline Material properties & Silicon & $\mathrm{SiC}$ \\
\hline Young's modulus $(\mathrm{GPa})$ & 1.69 & 4.70 \\
\hline Poisson ratio & 0.30 & 0.22 \\
\hline Density $\left(\mathrm{kg} / \mu \mathrm{m}^{-3}\right)$ & $2.5 \times 10^{-15}$ & $3.2 \times 10^{-15}$ \\
\hline TCE Integral Form $(1 / \mathrm{K})$ & $2.50 \times 10^{-6}$ & $2.30 \times 10^{-6}$ \\
\hline Thermal Conductivity $(\mathrm{pW} / \mathrm{umK})$ & $1.48 \times 10^{+8}$ & $5.0 \times 10^{+8}$ \\
\hline Specific Heat $(\mathrm{PJ} / \mathrm{kgK})$ & $7.12 \times 10^{14}$ & $1.34 \times 10^{15}$ \\
\hline
\end{tabular}

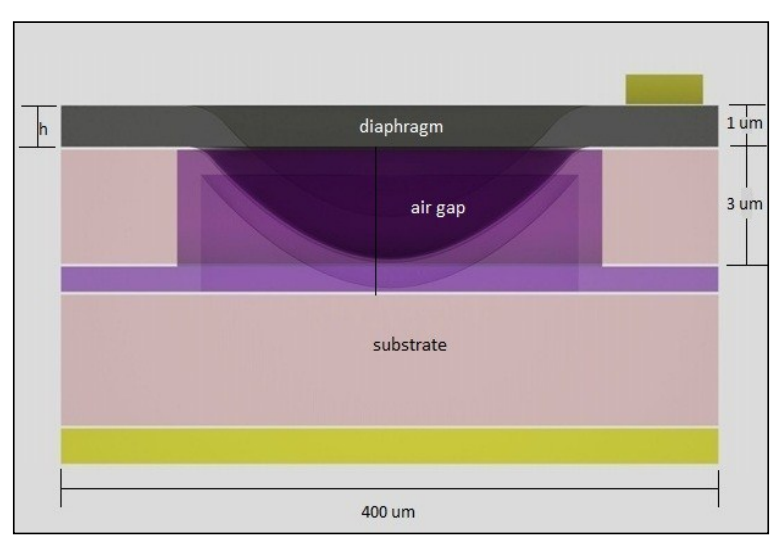

Fig. 1. Structural model for capacitive pressure sensor 
B. Theory of operation of the square deflection and maximum stress

For a two dimensional diaphragm with a pressure load, $p$, the differential equation for the displacement of the diaphragm can be derived by analyzing the balance conditions for forces and bending moments in an elemental area of diaphragm, $d x d y$. The general equation for displacement $w(x, y)$ is found to be the differential equation of diaphragm for displacement is given as equation (1), where we measure the point at the center of the diaphragm due to pressure applied on its surface:

$$
D\left[\frac{\partial^{4} w}{\partial x^{4}}+2 \frac{\partial^{4} w}{\partial x^{2} \partial y^{2}}+\frac{\partial^{4} w}{\partial y^{4}}\right]+h \rho \frac{\partial^{2} w}{\partial t^{2}}=p(x, y)(1)
$$

This equation is based on time dependence, so it can be used for frequency analysis. $D$ is the flexural rigidity, $h$ is the diaphragm's thickness and $\rho$ is density of the diaphragm material. If the pressure $p$ is uniform then the steady displacement can be expressed as equation (2):

$$
D\left[\frac{\partial^{4} w}{\partial x^{4}}+2 \frac{\partial^{4} w}{\partial x^{2} \partial y^{2}}+\frac{\partial^{4} w}{\partial y^{4}}\right]=p(2)
$$

For a square diaphragm with a side length of $2 a$ as shown in Figure 2, the simplest expression of displacement for a pressure $p$ can be expressed by equation (3) [5]:

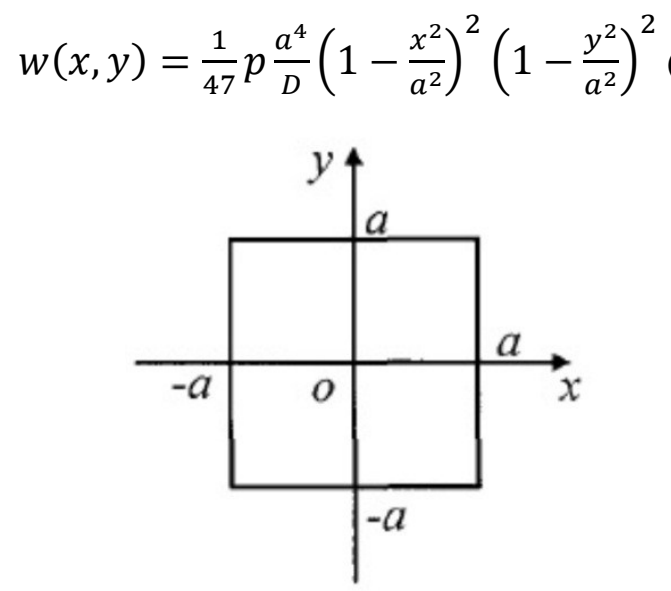

Fig. 2. Structure geometries of a square diaphragm

Since the deflection of the diaphragm is higher than its thickness, the strain in the middle plane of the diaphragm could be neglected. Thus the diaphragm stresses as well as the maximum stresses components for normal stress on surfaces perpendicular to $x$ axis $\left(\sigma_{x}\right)$ and normal stress on surfaces perpendicular to $y$ axis $\left(\sigma_{y}\right)$ were considered. The equations for diaphragm stresses are as follows equation(4) and (5):

$$
\sigma_{x}=-\frac{E}{1-v^{2}}\left[\frac{\partial^{2} w}{\partial x^{2}}+v \frac{\partial^{2} w}{\partial y^{2}}\right]-\frac{E \alpha \Delta T}{1-v}(4)
$$

$$
\sigma_{y}=-\frac{E}{1-v^{2}}\left[\frac{\partial^{2} w}{\partial y^{2}}+v \frac{\partial^{2} w}{\partial x^{2}}\right]-\frac{E \alpha \Delta T}{1-v}(5)
$$

Note that $E$ is Young's modulus, $v$ is Poisson's ratio of the diaphragm material, $w$ is vertical deflection of the diaphragm, $\alpha$ equal to $\varepsilon / \Delta T$, where $\varepsilon$ is strain and $\Delta T$ is temperature change with respect to reference temperature.

\section{SimULATION AND RESUltS}

\section{A. Simulation Settings}

CoventorWare ver.2008 simulation software is used in this research to design, simulate and modify the performance of MEMS capacitive pressure sensor. It has three main components: Architect, Designer and Analyzer [6]. Architect is used to design the schematic of the capacitive pressure sensor. Designer is used to build the 3D design of the diaphragm. Analyzer is used to analyze the diaphragm deflection with given pressure and temperature.

$\mathrm{Si}$ and $3 \mathrm{C}-\mathrm{SiC}$ materials with their respected electrical and mechanical properties are used to simulate the movable diaphragm (top plate). The anode (top plate) and cathode (bottom plate) separation is set to be $3 \mu \mathrm{m}$, and the range of applied pressures is between 0 to $100 \mathrm{MPa}$. The design steps include selecting the substrate layer and wet etching of the backside of the substrate to create the membrane. The next process is mesh creation for the device that is essential to allow the Analyzer to do the pressure and temperature analysis. Both are performed using CoventorWare mechanical solver MemMech. Figure 3 and Figure 4 shows the diaphragm deformation and maximum stress under a series of different pressures, respectively.

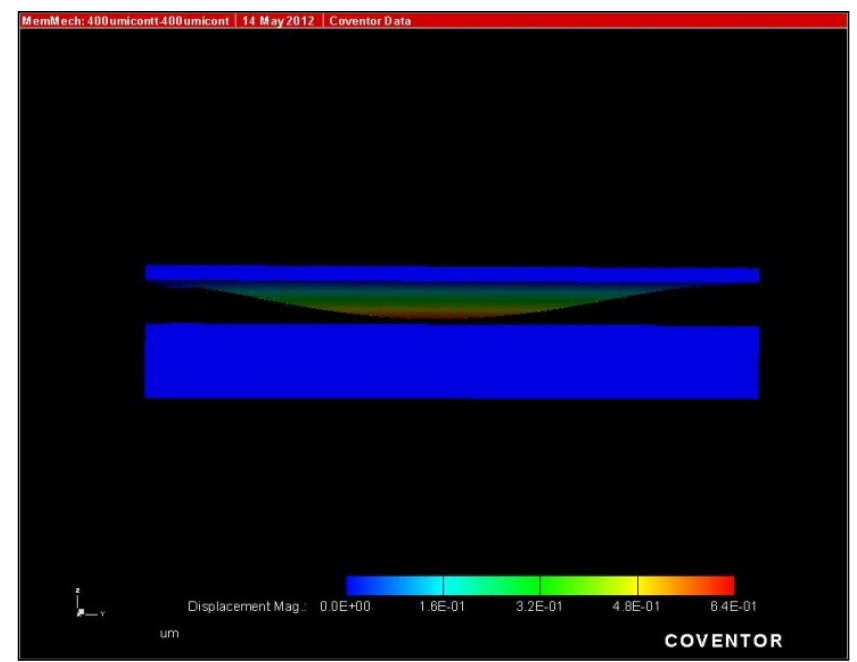

Fig. 3. Deflection of diaphragm by applied pressure 


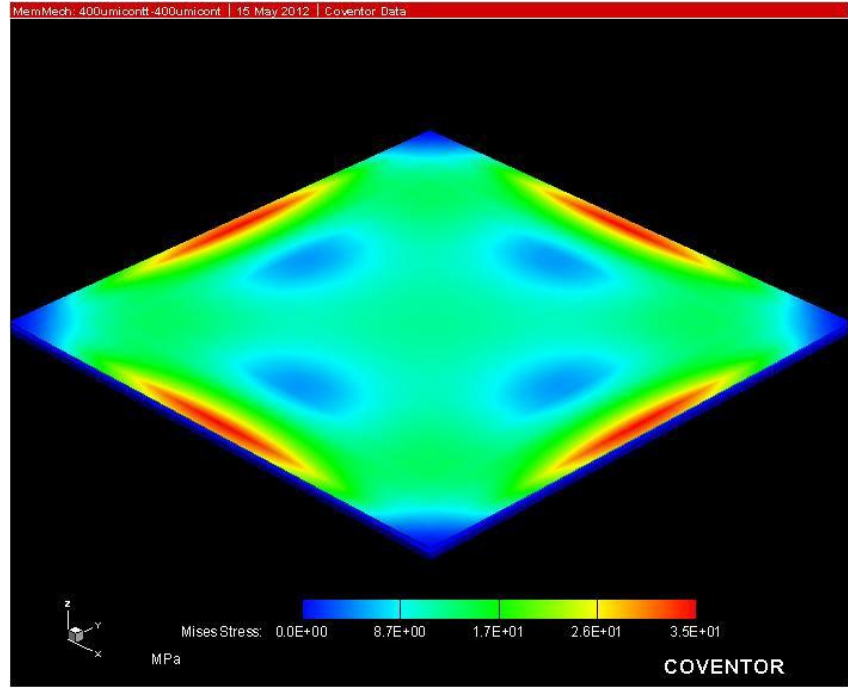

Fig. 4. Maximum stress of diaphragm by applied pressure

Figure 5 shows the 3D model of the diaphragm using mapped bricks mesh generated by Designer [7]. There are three steps involved. Firstly is the substrate step, secondly is the silicon planar fill with an anistropic front side wet etch, and thirdly $\mathrm{Si} / \mathrm{SiC}$ top diaphragm by using stack material modeling action. The substrate layer material is silicon. The wet etch properties are $3 \mu \mathrm{m}$ depth and $54.7^{\circ}$ degree angle of the silicon substrate. The highest stress-deflection of the diaphragm for an applied pressure of $100 \mathrm{MPa}$ is at the center of the diaphragm. The resulting diaphragm stress-deflection at $3 \mu \mathrm{m}$ considered as the touch-mode deflection. But in this paper, we are focuses on the deflection of the diaphragm only.

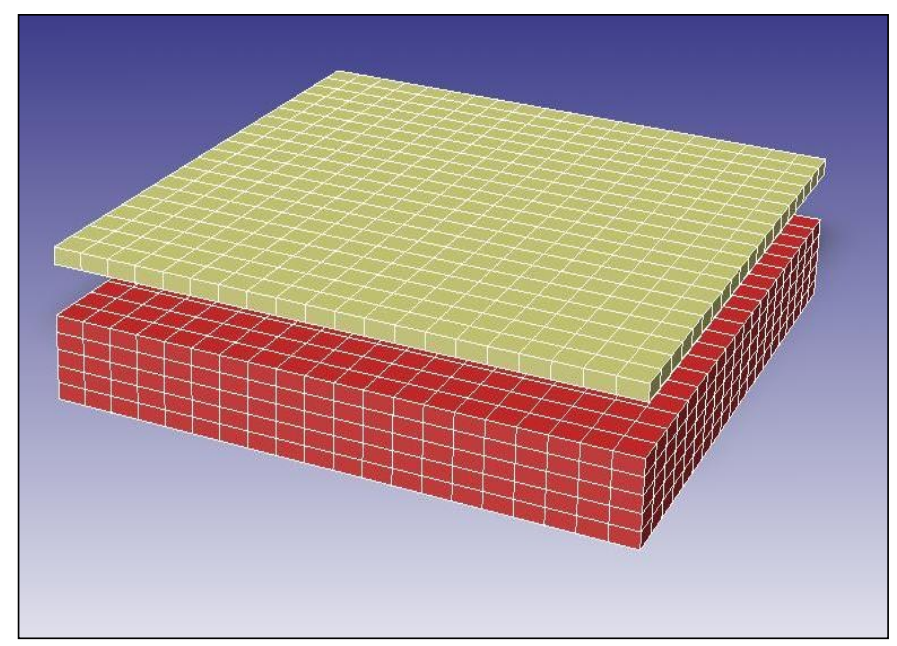

Fig. 5. 3D diaphragm model using mapped brick mesh with relevant boundary conditions.

\section{B. Results and discussion}

The capacitive pressure sensor is subjected to a range of temperatures namely $27^{\circ} \mathrm{C}, 300^{\circ} \mathrm{C}, 700^{\circ} \mathrm{C}$ and $1000^{\circ} \mathrm{C}$. The reference temperature is at $27^{\circ} \mathrm{C}$, where we assume that the diaphragm is stress free. It is also assumed that by heating the diaphragm rapidly, the deflection is achieved without relaxation. Symmetric boundary conditions have been chosen for the planes at $\mathrm{x}=200 \mu \mathrm{m}$ and $\mathrm{y}=200 \mu \mathrm{m}$, where the pressure is applied at the center of the diaphragm.

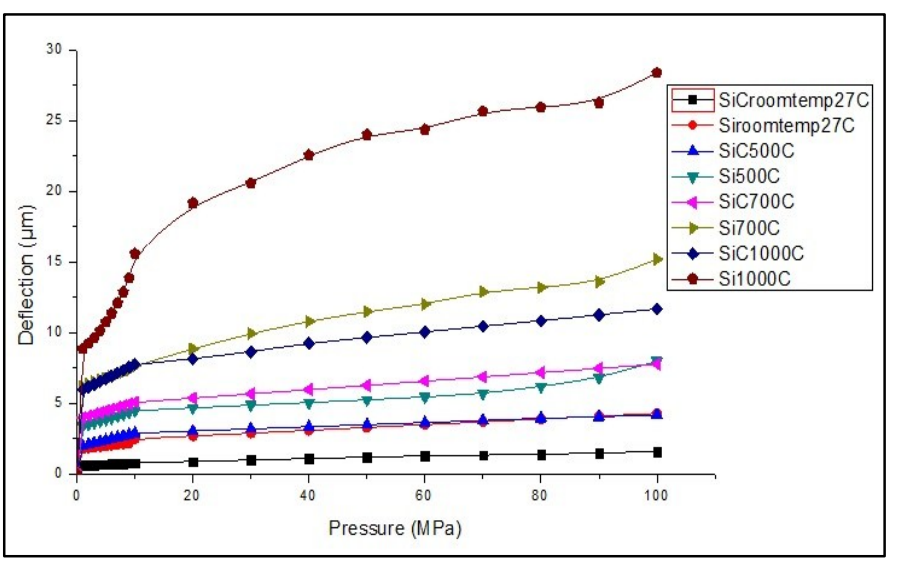

Fig. 6.Deflection at differential pressures and temperatures with the diaphragm thickness of $1 \mu \mathrm{m}$

TABLE II:

Linear Regression Analysis For Deflection Results at DifFERENTIAL TEMPERATURES With THICKNESS OF $1 \mu \mathrm{M}$

\begin{tabular}{|l|l|l|l|l|}
\hline \multicolumn{2}{|c}{$\begin{array}{l}\text { Temperature } \\
\left({ }^{\circ} \mathrm{C}\right)\end{array}$} & \multicolumn{2}{|c|}{$\mathrm{SiC}$} & \multicolumn{2}{c|}{$\mathrm{Si}$} \\
\cline { 2 - 5 } & Equation & $\mathrm{R}^{2}$ & Equation & $\mathrm{R}^{2}$ \\
\hline 27 & $\mathrm{y}=0.008 \mathrm{x}+0.74$ & 1.00 & $\mathrm{y}=0.020 \mathrm{x}+2.30$ & 1.00 \\
\hline 500 & $\mathrm{y}=0.014 \mathrm{x}+2.77$ & 1.00 & $\mathrm{y}=0.033 \mathrm{x}+3.81$ & 0.87 \\
\hline 700 & $\mathrm{y}=0.03 \mathrm{x}+4.78$ & 1.00 & $\mathrm{y}=0.075 \mathrm{x}+7.44$ & 0.98 \\
\hline 1000 & $\mathrm{y}=0.043 \mathrm{x}+7.38$ & 1.00 & $\mathrm{y}=0.122 \mathrm{x}+16.54$ & 0.92 \\
\hline
\end{tabular}

Figure 6 and Table II showed the deflection of the $1 \mu \mathrm{m}$ diaphragm made of $\mathrm{SiC}$ and $\mathrm{Si}$ under a differential temperatures. At room temperature, the deflection at the center of the diaphragm for both $\mathrm{SiC}$ and $\mathrm{Si}$ increases linearity (Rsquared value $=1.00$ ) from $0-100 \mathrm{MPa}$. It is observed that the elastic limit of both materials can sustain $100 \mathrm{MPa}$ at room temperature.

However, this linear trend does not hold for $\mathrm{Si}$ at high temperatures. The deflection of Si diaphragm increases nonlinearly for $500^{\circ} \mathrm{C}, 700^{\circ} \mathrm{C}$ and $1000^{\circ} \mathrm{C}$ with $\mathrm{R}$-squared value at $0.87,0.98$ and 0.92 , respectively. On the other hand, the deflection of the $\mathrm{SiC}$ diaphragm increases at high temperatures up to $1000^{\circ} \mathrm{C}$, all with R-square value of 1 .

The maximum deflection of the center of the diaphragm for $\mathrm{SiC}$ and silicon at $100 \mathrm{MPa}$ yields predicted result, where $\mathrm{Si}$ diaphragm deflects more compares to $\mathrm{SiC}$ diaphragm. At room temperature, the deflection for both $\mathrm{Si}$ and $\mathrm{SiC}$ diaphragm are $1.6 \mu \mathrm{m}$ and $4.3 \mu \mathrm{m}$, respectively. At $1000^{\circ} \mathrm{C}$, both $\mathrm{Si} / \mathrm{SiC}$ diaphragms deflect $11.7 \mu \mathrm{m} / 28.4 \mu \mathrm{m}$, respectively. The Young modulus of $\mathrm{SiC}$ is approximately 3 times higher compares to $\mathrm{Si}$, and hence, the $\mathrm{SiC}$ deflection is three time less [8]. It must also be pointed out that the silicon diaphragm shows non-linear deflection at high temperatures because of the stress due the stretching of the diaphragm [9]. In other words, Si diaphragm cannot sustain the loading pressure at such extreme environment. 
For the capacitive pressure sensor to be used continuously over a long period of time, the diaphragm must be capable of responding to applied pressure and extremely temperature, and must retain its elastic property [10]. This analysis indicates that $\mathrm{SiC}$ diaphragm is indeed is much better suited for extreme environments than $\mathrm{Si}$.

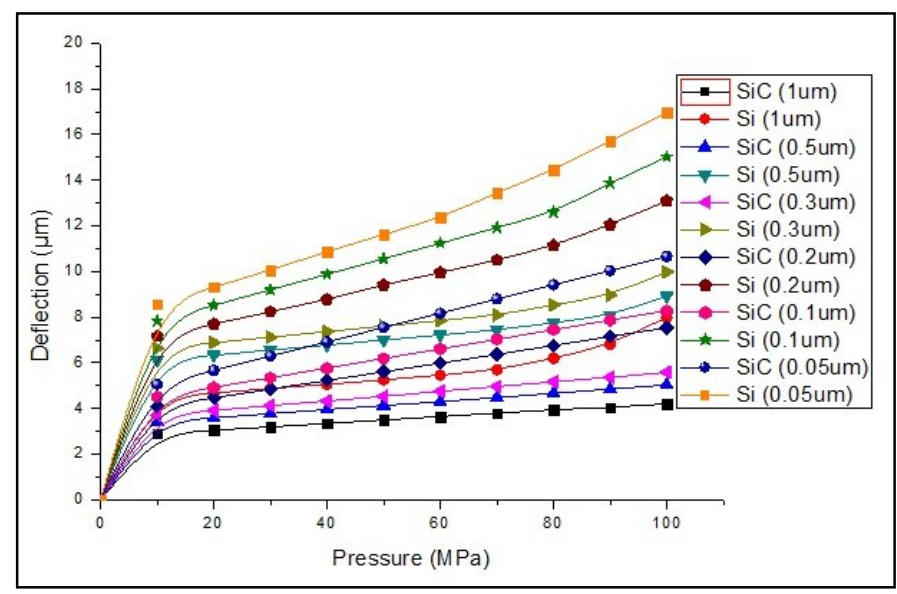

Fig. 7. Results of deflection at differential thickness of diaphragm at $500^{\circ} \mathrm{C}$ with thickness diaphragm of $0.05 \mu \mathrm{m}, 0.1 \mu \mathrm{m}, 0.2 \mu \mathrm{m}$ and $1.0 \mu \mathrm{m}$

TABLE III

Linear Regression Analysis For Deflection DifFerent Thickness at $500^{\circ} \mathrm{C}$

\begin{tabular}{|l|l|l|l|l|}
\hline \multirow{2}{*}{$\begin{array}{l}\text { Thickness } \\
(\mu \mathrm{m})\end{array}$} & \multicolumn{2}{|c|}{$\mathrm{SiC}$} & \multicolumn{2}{c|}{$\mathrm{Si}$} \\
\cline { 2 - 5 } & Equation & $\mathrm{R}^{2}$ & Equation & $\mathrm{R}^{2}$ \\
\hline 0.05 & $\mathrm{y}=0.062 \mathrm{x}+4.43$ & 1.000 & $\mathrm{y}=0.091 \mathrm{x}+7.32$ & 0.988 \\
\hline 0.10 & $\mathrm{y}=0.042 \mathrm{x}+4.09$ & 1.000 & $\mathrm{y}=0.076 \mathrm{x}+6.87$ & 0.987 \\
\hline 0.20 & $\mathrm{y}=0.038 \mathrm{x}+3.70$ & 1.000 & $\mathrm{y}=0.063 \mathrm{x}+6.33$ & 0.987 \\
\hline 0.30 & $\mathrm{y}=0.020 \mathrm{x}+3.50$ & 0.999 & $\mathrm{y}=0.032 \mathrm{x}+6.11$ & 0.933 \\
\hline 0.50 & $\mathrm{y}=0.017 \mathrm{x}+3.23$ & 0.999 & $\mathrm{y}=0.027 \mathrm{x}+5.70$ & 0.949 \\
\hline 1.00 & $\mathrm{y}=0.014 \mathrm{x}+2.77$ & 0.998 & $\mathrm{y}=0.033 \mathrm{x}+3.81$ & 0.873 \\
\hline
\end{tabular}

Figure 7 and Table III show the diaphragm deflection at $500^{\circ} \mathrm{C}$ at the different thicknesses. As shown in equation (3), the deflection is inversely proportional to the thickness. Moreover, Si diaphragms have larger deflection $(16.96 \mu \mathrm{m})$ compare to $\mathrm{SiC}$ diaphragm $(10.66 \mu \mathrm{m})$ at the thickness of $50 \mathrm{~nm}$. More importantly, the SiC diaphragm has more linear deflection compares to $\mathrm{Si}$ diaphragm at all thicknesses, as shown in Table III. We also observe the mechanical failure of $\mathrm{Si}$ diaphragm at $1000^{\circ} \mathrm{C}$, which is due to the degradation of the surface of $\mathrm{SiC}$ diaphragm [11]. On the other hand, show consistent linearity throughout different thicknesses at such high pressure and temperature as recorded in Table III. It implies that very thin diaphragm below $1 \mu \mathrm{m}$ of the capacitive pressure sensor should be use $\mathrm{SiC}$ material indicating a very high mechanical strength of the diaphragm that can able to survive a very high pressure and temperature without fracture [12]. These deflection results are useful in real fabrication practical applications by specified the parameter of the diaphragm.

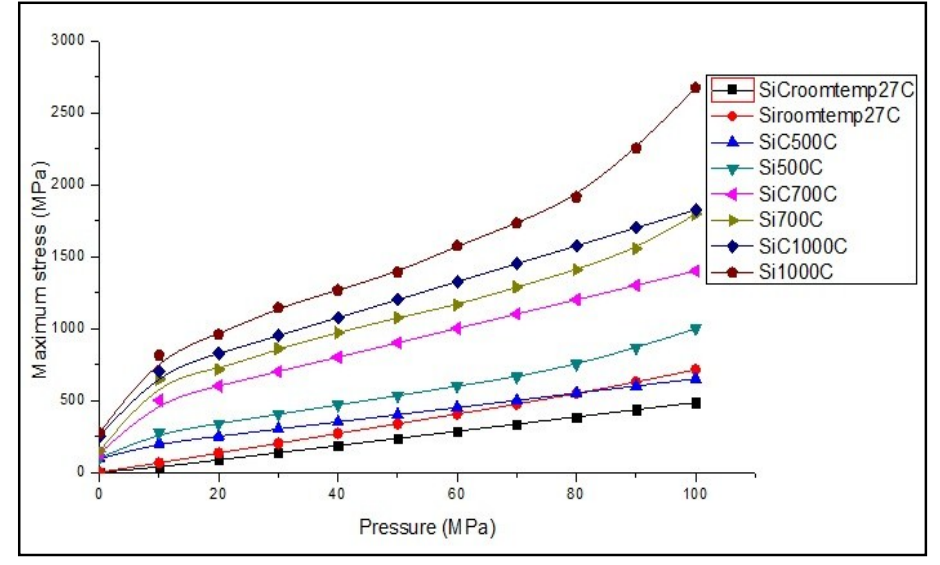

Fig. 8. Results of maximum stress atdifferential temperature with the thickness diaphragm for $0.2 \mu \mathrm{m}$

TABLE IV

Linear Regression Analysis for MaXimum Stress at Different Thickness AT $500^{\circ} \mathrm{C}$

\begin{tabular}{|l|l|l|l|l|}
\hline \multirow{2}{*}{$\begin{array}{l}\text { Temperature } \\
\left({ }^{\circ} \mathrm{C}\right)\end{array}$} & \multicolumn{2}{|c|}{$\mathrm{SiC}$} & \multicolumn{2}{c|}{$\mathrm{Si}$} \\
\cline { 2 - 5 } & Equation & $\mathrm{R}^{2}$ & Equation & $\mathrm{R}^{2}$ \\
\hline 27 & $\mathrm{y}=5 \mathrm{x}-15$ & 1.000 & $\mathrm{y}=7.098 \mathrm{x}-13.2$ & 0.998 \\
\hline 500 & $\mathrm{y}=5 \mathrm{x}+150$ & 1.000 & $\mathrm{y}=7.643 \mathrm{x}+168.7$ & 0.981 \\
\hline 700 & $\mathrm{y}=10 \mathrm{x}+400$ & 1.000 & $\mathrm{y}=12.13 \mathrm{x}+480.2$ & 0.985 \\
\hline 1000 & $\mathrm{y}=12.5 \mathrm{x}+575$ & 0.996 & $\mathrm{y}=18.92 \mathrm{x}+531.2$ & 0.959 \\
\hline
\end{tabular}

The mechanical characterization to investigate the maximum stress on the diaphragm is performed using "Mises Stress" simulation. Figure 8 and Table IV show the maximum stress of a $200 \mathrm{~nm}$ thick diaphragm at the temperatures of $27^{\circ} \mathrm{C}$, $500^{\circ} \mathrm{C}, 700^{\circ} \mathrm{C}$ and $1000^{\circ} \mathrm{C}$.In theory as shown in equation (4) and (5), the stress diaphragm is proportional to the pressure and temperature. The stress distribution increases with the increment of pressure and temperature, however the stresses are less by using $\mathrm{SiC}$ material compare to $\mathrm{Si}$. The temperature shows a significant influence of the diaphragm on the stress state.

The main point from Figure 8 is the fact that the $\mathrm{SiC}$ diaphragm has more linear stresses versus pressure as compares to $\mathrm{Si}$ diaphragm at all temperatures, as shown in Table IV. Amazingly, even at $1000^{\circ} \mathrm{C}$ the $\mathrm{SiC}$ diaphragm shows linear graph $(\mathrm{R}$-squared $=0.996)$, which Si diaphragm shows a non-linear maximum stress (R-squared value = 0.959).

These results show that the maximum stress of the $\mathrm{SiC}$ diaphragm at $1825 \mathrm{MPa}$ is much below the yield strength of the $\mathrm{SiC}$ material at $3440 \mathrm{MPa}$. Similarly, the maximum stress for silicon diaphragm is $2000 \mathrm{MPa}$, whereas the yield strength for silicon is $2673 \mathrm{MPa}$ [13]. Further analysis will be carried out to investigate this finding.

\section{CONCLUSION}

This paper simulates and compares the performances of a parallel-plate model of a pressure sensor, where the top movable plate is made of either $3 \mathrm{C}-\mathrm{SiC}$ or $\mathrm{Si}$. The movable square diaphragm has the area of $400 \mu \mathrm{m}^{2}$ with six different thicknesses $(0.05,0.1,0.2,0.3,0.5 \mu \mathrm{m}$ and $1.0 \mu \mathrm{m})$. The 
mechanical stress-deflection is performed by loading high pressure and temperature up to $100 \mathrm{MPa}$ and $1000^{\circ} \mathrm{C}$, respectively. The $1 \mu \mathrm{m}$ thick $\mathrm{SiC}$ diaphragm exhibits close linearity graph with R-squared value of 1 , and the maximum deflection of $11.7 \mu \mathrm{m}$, whereas the Si diaphragm of the same thickness exhibits non-linear behavior with $\mathrm{R}$-square value of 0.92 , and maximum deflection of $28.4 \mu \mathrm{m}$ at the applied pressure and temperature of $100 \mathrm{MPa}$ and $1000^{\circ} \mathrm{C}$, respectively. $\mathrm{SiC}$ diaphragm consistently shows better linearity (in term of R-square values) over $\mathrm{Si}$ diaphragm with the stress simulation as well. The $200 \mathrm{~nm}$ thick diaphragm shows the R-square value of 0.996 at the extreme temperatures and pressures. Finally, it is shown that the maximum stresses of both $\mathrm{SiC}$ and $\mathrm{Si}$ are lower than the yield strength of both materials.

\section{ACKNOWLEDGMENT}

The authors would like to thank the Institute Microengineering and Nanoelectronics (IMEN) of Universiti Kebangsaan Malaysia (UKM), Queensland Micro- and Nanotechnology Centre (QMNC) of Griffith University for providing the resources and facilities to perform this project. This work was performed in part at the Queensland node of the Australian National Fabrication Facility, a company established under the National Collaborative Research Infrastructure Strategy to provide nano and microfabrication facilities for Australia's researchers.

\section{REFERENCES}

[1] R. S. Okojie, G. M. Beheim, G. J. Saad and E. Savrun, Characteristic of a hermetic $6 \mathrm{H}-\mathrm{SiC}$ pressure sensor at $600^{\circ} \mathrm{C}$, Conference and Exposition, 2001.

[2] Y. Hezarjaribi, M. N. Hamidon, S. H. Keshmiri and A. R. Bahadorimerhr, Capacitive pressure sensors based on MEMS, operating in harsh environments, ICSH proceedings, 2008.

[3] M. Mehregany and C. A. Zorman, SiC MEMS: opportunities and challenges for applications in harsh environments, Journal of Elsevier, Thin solid film, 1999, pp. 355-356.

[4] R. Pratap and A. Arunkumar, Material selection for MEMS devices, Indian Journal of Pure and Applied Physics, 2007, pp. 358-367

[5] S. Timshenko and S. Woinosky-Krieger, Theory of Plates and Shells, McGraw Hill Classic Textbook Ressue, 1987.

[6] I. A. Ali, Micromachining techniques for fabrication micro and nano structures, 2009, pp. 227-298.

[7] M. Young, The Technical Writer's Handbook.Mill Valley, CA: University Science, 1989.

[8] Shanmugavalli, M. Uma, G. Vasuki and M. Umapathy, Design and simulation of MEMS using interval analysis. Journal of physics: Conference series 34, 2006, pp. 601-605.

[9] D. J. Yiung, J. Du, C. A. Zorman and W. H. Ko, High-temperature single-crystal 3C-SiC capacitive pressure sensor, IEEE sensors journal, vol.4, 2004, pp. 464-470.

[10] Ganji, B. A. and Majlis, B. Y. (2009). Design and fabrication of a new MEMS Capacitive Microphone Using a Perforated Aluminum Diaphragm. Sensors and Actuators A: Physical, 149: pp.29-37.

[11] E. Tobin, M. Magida, S. Kishner and M. Krim, Design, fabrication and test of a meter-class reaction bonded SiC mirror blank, SPIE vol.2543.

[12] Kudimi, J. M. R., MohdYasin, F. and Dimitrijev, S., SiC-Based Piezoelectric Energy Harvester for Extreme Environment

[13] The Engineering Toolbox, Elastic Properties and Young Modulus for Some Materials retrieved April 20, 2012 from http://www.engineeringtoolbox.com/young-modulus-d_417.html 